\title{
CONFLICTOS INDIVIDUALES DE SEGURIDAD SOCIAL. DESACIERTOS E INCOMPETENCIA EN SU RESOLUCIÓN*
}

\author{
INDIVIDUAL SOCIAL SECURITY CONFLICTS. DEFICIENCIES \\ AND INCOMPETENCE IN ITS RESOLUTION \\ CONFLITS INDIVIDUELS DE SÉCURITÉ SOCIALE. \\ ERREURS ET INCOMPETENCE DANS LA RÉSOLUTION
}

\section{Verónica Lidia MARTÍNEZ MARTÍNEZ**}

RESUMEN: El presente artículo analiza las deficiencias e irregularidades que presentan los conflictos individuales de seguridad social, creados en la reforma laboral de 2012.

Palabras clave: Conflictos individuales de seguridad social, procedimiento especial.

ABSTRACT: The present article examines the deficiencies and irregularities which individual social security conflicts, created by the 2012 labor's act reform.

Key Words: Individual social security conflicts, special procedure.

RÉSUMÉ: Le présent article analyse les lacunes et irrégularités que présentent les conflits individuels de la sécurité sociale, créé par la réforme du code du travail en 2012.

Mots-clés: Conflits individuels de sécurité sociale, les procédures spéciales.

\footnotetext{
* Recibido el 30 de abril de 2014 y aceptado para su publicación el 23 de marzo de 2015.

** Especialista en derecho social y maestra en derecho por la División de Estudios de Posgrado de la Facultad de Derecho de la UNAM; miembro de la Academia Mexicana de Derecho de la Seguridad Social (vero_nichecap@hotmail.com).
} 
SUMARIO: I. Introducción. II. La equívoca denominación de "conflictos individuales de seguridad social". III. Regulación de los procedimientos especiales. IV. Aspecto procesal de los conflictos individuales de seguridad social. V. Problemática que presentan los conflictos individuales de seguridad social. VI. Fuentes de información.

\section{INTRODUCCIÓN}

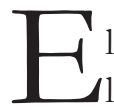
130 de noviembre de 2012 se publicó en el Diario Oficial de la Federación la reforma a la Ley Federal del Trabajo, que introduce la figura jurídica de los conflictos individuales de seguridad social, a los cuales al ubicarlos como procedimientos especiales, los sujeta a las reglas contenidas en el capítulo XVIII, artículos 892 a 899 y 899-A al 899-G del Código Obrero, abandonándose su interposición, tramitación y resolución bajo el procedimiento ordinario.

Partiendo del análisis de los términos "seguridad social" y "seguro social", el presente trabajo estudia la denominación de conflictos individuales de seguridad social, así como su origen, su regulación, su aspecto procesal y la incompetencia de la autoridad laboral que tramita y resuelve este tipo de controversias, aunada a su desafortunada incorporación y regulación en la actual Ley Federal del Trabajo, cuyo ámbito de aplicación evidencia que no es el ordenamiento idóneo para regularlas.

\section{LA EQUÍVOCA DENOMINACIÓN DE “CONFLICTOS INDIVIDUALES DE SEGURIDAD SOCIAL"}

Particularmente, la estrecha vinculación que existe entre los términos "seguridad social" y "seguro social”, así como su empleo como sinónimos — sin serlo-, han generado múltiples, confusas y contradictorias definiciones en torno a ambas expresiones, que hacen necesaria su diferenciación con base en la doctrina de los principales tratadistas sociales y en los diversos ordenamientos que se han ocupado de regularlos.

En este tenor, para Netter, el objeto de la seguridad social es crear, en beneficio de todas las personas — sobre todo de los trabajadores-, un conjunto de garantías contra ciertas contingencias que pueden reducir o suprimir su actividad, o bien imponerles gastos suplementarios cuyos objetivos no se 
limitan a la cobertura (más o menos completa) de los gastos o la reparación (más o menos completa) de las consecuencias que trae consigo la realización de las contingencias previstas, en la medida en que éstas tienen como resultado la alteración del nivel de vida de los individuos, sino implica la prevención, o sea, las medidas destinadas a evitar la aparición de contingencias que pueden traer consigo daños físicos o económicos a las personas. ${ }^{1}$

Así, ante la doble función que cumple la seguridad social — como paliativo frente a los diversos riesgos que puedan presentarse y la prevención de los mismos-, Francisco de Ferrari establece que la seguridad social recurre a una idea más amplia y ambiciosa que la que sirvió de base a los simples seguros sociales, los cuales se han limitado en promover poderosas organizaciones de previsión social, utilizando el cálculo actuarial y la posibilidad de descontar del salario de los trabajadores, por mandato legal, la cotización mensual para el sostenimiento de los servicios, además de concretarse casi exclusivamente a la previsión y reparación de los daños derivados de la enfermedad, vejez e invalidez; es decir, a la limitación del hecho consumado y a encontrarle un remedio. ${ }^{2}$

La seguridad social, puntualiza Ferrari, es otra cosa, pues si bien, como ocurre con los seguros sociales, pone a grandes organizaciones al servicio del hombre, lo fundamental de la seguridad social es que ella realiza una gran síntesis y proclama el derecho que tiene todo hombre a que la sociedad le asegure un mínimo de vida digna y decorosa.

De esta manera, los seguros sociales representan una parte de la seguridad social, como lo son los demás organismos privados, estatales, que cumplen en la sociedad contemporánea una finalidad similar destinada a asegurar mínimos de vida humana, ${ }^{3}$ teniendo, de acuerdo con Henry Richardson, su principal rasgo distintivo en el hecho de que los seguros sociales son financiados con contribuciones de los beneficiarios o en nombre de éstos, por sus patronos, existiendo una relación entre las contribuciones y los beneficios. ${ }^{4}$

1 Netter, F., La seguridad social y sus principios, trad. de Julio Arteaga, México, Instituto Mexicano del Seguro Social, 1982, p. 9.

2 Ferrari, Francisco de, Los principios de la seguridad social, Uruguay, Biblioteca de Publicaciones Oficiales de la Facultad de Derecho y Ciencias Sociales de la Universidad de Montevideo, 1955, p. 102.

3 Ibidem, pp. 102 y 103.

4 Richardson, J. Henry, La seguridad social aspectos económicos y financieros, Buenos Aires, Victor Lerú, 1962, pp. 65-67. 
Por ello, de acuerdo con la Conferencia Internacional del Trabajo, al abarcar la seguridad social todas las medidas relacionadas con las prestaciones, en efectivo o en especie, encaminadas a garantizar una protección en determinados casos; por ejemplo, la falta de ingresos laborales (o ingresos laborales insuficientes), debido a enfermedad, discapacidad, maternidad, accidentes de trabajo, desempleo, vejez o muerte de un miembro de la familia; la falta de acceso, o acceso a precios excesivos, a la asistencia médica; un apoyo familiar insuficiente —en particular para los hijos y adultos a cargo-; la pobreza generalizada, y la exclusión social, ${ }^{5}$ se vale de diversos medios, siendo uno de ellos el seguro social, ${ }^{6}$ cuyas características, de acuerdo con la Organización Internacional del Trabajo (OIT), son:

- Su financiamiento se asegura mediante cotizaciones, comúnmente, tanto de los empleadores como de los trabajadores, contribuyendo a veces el Estado con el subsidio o aporte adicional del erario.

- La afiliación obligatoria, salvo contadas excepciones.

- Las cotizaciones ingresan en cajas especiales a cuyo cargo está el pago de las prestaciones.

- Los fondos que no se necesitan para pagar las prestaciones corrientes son invertidos para que produzcan ingresos suplementarios.

- El derecho de una persona a acceder a las prestaciones deriva de las cotizaciones que ha pagado, sin que deba demostrar para ello su carencia de recursos.

- El monto tanto de las cotizaciones como de las prestaciones guarda a menudo relación con los ingresos que el afiliado percibe o percibía.

- Los regímenes del seguro de accidentes del trabajo y enfermedad profesional son, regularmente, financiados en su totalidad por los empleadores, aunque a veces hay un aporte de fondos públicos. ${ }^{7}$

- Constituye uno de los elementos que contribuyen a conformar los amplios regímenes de la seguridad social, definida por la OIT como la protección que la sociedad proporciona a sus miembros, mediante una

5 Organización Internacional del Trabajo, Introducción a la seguridad social, 3a. ed., Ginebra, OIT, 1984, p. 9.

6 Rouzaut, Adolfo, Fundamento constitucional de la seguridad social, Argentina, Instituto de Derecho Constitucional, 1962, p. 36.

7 Organización Internacional del Trabajo, op. cit., pp. 4 y 5. 
serie de medidas públicas contra las privaciones económicas y sociales, que de otra manera derivarían en la desaparición o fuerte reducción de sus ingresos a consecuencia de la enfermedad general, maternidad, accidente de trabajo o enfermedad profesional, desempleo, invalidez, vejez y muerte, así como la protección en forma de asistencia médica y de ayuda a las familias con hijos. ${ }^{8}$

De acuerdo con Pérez Leñero, quien realiza un estudio gnoseológico de la seguridad social, los seguros sociales no son toda la seguridad social; por ello, no pueden confundirse estos dos términos. Los seguros sociales — puntualiza el jurista ibérico- son el instrumento técnico más eficaz para la realización de una finalidad: la seguridad social, pero no agotan todo su contenido. Los seguros sociales (su misma pluralidad nos lo dice) son parciales, inadecuados; en cambio, la seguridad social es integral y unitaria o no es nada, ${ }^{9}$ pues tiene por fin defender y propulsar la paz y prosperidad general de la sociedad a través del bienestar individual de todos sus miembros. ${ }^{10}$

Igualmente, para Almansa Pastor existe una marcada diferencia entre los términos "seguro social" y "seguridad social", pues dice que el primero tiende a reparar las consecuencias de eventos previstos (y sólo en cuanto hayan sido previstos; es decir, asegurados con antelación), siempre que se trate de necesidades de concreción individual y de posible evaluación económica.

La seguridad social no sólo atiende a la reparación, sino vela por la prevención para que no se produzca la necesidad, y le interesa la recuperación del individuo, a fin de devolverlo a la situación en que se hallaba antes de producirse la necesidad, ya que no sólo protege en cuanto que la necesidad haya sido prevista y asegurada con anterioridad, sino también en cualquier circunstancia en que aquélla se produzca y una vez producida; además, no se concreta a proteger necesidades individuales y económicamente evaluables, sino también aquéllas cuya protección sólo puede hacerse colectivamente, así como las necesidades morales y espirituales. ${ }^{11}$

En nuestro país, el tratadista Alberto Briceño Ruiz establece que la seguridad social no es ciencia ni disciplina jurídica, sino el conjunto de institucio-

8 Ibidem, p. 3.

9 Pérez Leñero, José, Fundamentos de la seguridad social, Madrid, Aguilar, 1956, p. 14.

10 Ibidem, p. 35

11 Almansa Pastor, José Manuel, Derecho de la seguridad social, Madrid, Tecnos, 1973, p. 72. 
nes, principios, normas y disposiciones que protegen a todos los elementos de la sociedad contra cualquier contingencia que pudieran sufrir, y permite la elevación humana en los aspectos psicofísico, moral, económico, social y cultural; ${ }^{12}$ asimismo, se diferencia del seguro social, en cuanto a que este último se propone proteger a ciertas personas consideradas como integrantes de grupos económicos activos, frente a determinadas contingencias que pueden disminuir o extinguir su capacidad orgánica funcional. ${ }^{13}$

Así, de acuerdo con las precitadas definiciones, la seguridad social y el seguro social se distinguen por los siguientes aspectos:

\section{- Cobertura.}

- Contraprestación que otorga.

- Financiamiento.

En lo concerniente al primer criterio diferenciador — la cobertura-, que involucra el aspecto subjetivo, en el caso de los seguros sociales es limitada, pues ampara a grupos determinados. En contraste, la seguridad social, al tener a la universalidad como principio básico, protege a todos los miembros de la sociedad, alcanzándose de esta forma una cobertura total.

El otro aspecto importante dentro de la cobertura es el tipo de protección que se otorga. En el caso de los seguros sociales se ampara al derechohabiente contra ciertas contingencias preestablecidas, en tanto que la seguridad social no sólo se concreta a cubrir todo tipo de contingencias, sino que además busca la recuperación del individuo, su reincorporación al ámbito laboral y la prevención.

Respecto a la contraprestación que se otorga en el régimen de seguros sociales básicos, cabe referir que el asegurado únicamente adquiere derecho a los beneficios económicos en razón de las cotizaciones que ha pagado, siendo el salario percibido la base para calcular las prestaciones que se le otorguen, llenando los requisitos previstos en una ley o contrato de trabajo, pues el seguro social no es un sistema de beneficencia pública, sino que es, tal y como señala Néstor de Buen, “un sistema egoísta”. Por el contrario, en la seguridad

12 Briceño Ruiz, Alberto, Derecho mexicano de los seguros sociales, México, Harla, 1987, pp. 15 y 16 .

13 Briceño Ruiz, Alberto, Derecho de la seguridad social, México, Oxford, 2010, p. 9. 
social, la necesidad es el único elemento necesario para obtener sus beneficios.

Ante el reconocimiento que hace la comunidad mundial a la seguridad social como un derecho humano de corte social, a través de diversos instrumentos —entre ellos destacan la Declaración Universal de los Derechos Humanos (artículos 22 y 25); la Declaración Americana de los Derechos y Deberes del Hombre (artículo XVI); el Pacto Internacional de Derechos Económicos, Sociales y Culturales (artículo 9o.), y la Convención Americana sobre Derechos Humanos (artículo 26)—, su respeto y acceso debe garantizarse por el Estado, único obligado a cubrir el costo de las prestaciones que otorga (derechos-prestacionales). ${ }^{14}$

A diferencia de lo anterior, en el caso de los seguros sociales su financiamiento (en la mayoría de los casos) corre a cargo del asegurado, el empleador y el Estado, quienes deberán realizar las correspondientes aportaciones, que servirán de base para determinar el monto de las prestaciones en dinero otorgadas al asegurado, ante el cumplimiento de los requisitos previstos en la ley correspondiente o la presencia de la contingencia, como acontece en el seguro de riesgos de trabajo.

En razón de lo expuesto, en nuestro país se considera prácticamente imposible la existencia de los denominados "conflictos de seguridad social", cuando ésta nunca ha sido puesta en marcha de manera integral, pues a la fecha existen distintos sistemas de seguros sociales que paulatinamente se han ido privatizando, al contemplarse en la Ley del Seguro Social la participación de distintos organismos privados de inversión, como lo son las administradoras

14 Es posible conceptualizar a los derechos prestacionales desde un sentido amplio y un sentido estricto. Primeramente, de acuerdo con Gavara, los derechos de prestación en sentido amplio, al ser sinónimos de pretensión estatal, permiten incluir bajo este concepto tanto a los derechos sociales, vinculados a una acción fáctica del destinatario y susceptibles de articularse en términos de acciones positivas, como a los derechos de carácter organizativo y procedimental, vinculados a una decisión pública del poder público e interrelacionados con la necesidad de articular una configuración legislativa sobre el objeto, alcance y contenido de los distintos derechos conectados a la categoría. Por su parte, siguiendo a Alexy, los derechos a acciones positivas se dividen en aquellos cuyo objeto es una acción fáctica (derecho a prestaciones en sentido estricto) y aquellos que su objeto es una acción jurídica (derecho a prestaciones en sentido amplio). Gavara de Cara, Juan Carlos, La dimensión objetiva de los derechos sociales, Barcelona, Bosch, 2001, p. 18, y Alexy, Robert, Teoría de los derechos fundamentales, 3a. reimp., trad. de Ernesto Garzón Valdés, Madrid, Centro de Estudios Políticos y Constitucionales, 2002, p. 186. 
de fondos para el retiro, las sociedades de inversión especializadas de fondos para el retiro y las instituciones de seguros como garantes de las pensiones en sus modalidades de renta vitalicia o retiros programados, en las que el principio de unidad de gestión a cargo del IMSS desaparece al trasladarse a la Comisión Nacional del Sistema de Ahorro para el Retiro (Consar).

Desafortunadamente, el Instituto Mexicano del Seguro Social dentro de la Consar tiene una representación minoritaria e intrascendente, en tanto que los asegurados, los beneficiarios y los empleadores carecen de ella, contraviniéndose el otro principio rector sobre el que descansa la seguridad social: la participación de los interesados, que permite que los obligados y beneficiarios intervengan en el sistema de seguridad social, pero sin desplazar al Estado en la función de gestor principal, siendo la mejor expresión de este último principio el establecimiento de administraciones mixtas donde los interesados tengan participación, ya que ellos son los principales beneficiarios con el resultado. ${ }^{15}$

En palabras llanas, ante la privatización del sistema de seguros sociales, el asegurado que más cotice y acumule recursos en su cuenta individual obtendrá seguramente una mayor pensión, siempre que cumpla con los requisitos que prevé la legislación. En contraste, el asegurado que gane lo mínimo sólo podrá aspirar a obtener la pensión mínima garantizada por el Estado; con esto se impone un sistema de ahorro privado forzoso que fortalece el individualismo, pero que rompe con el principio esencial de la solidaridad, sin el cual no puede entenderse a la seguridad social.

Por todo ello, se considera que el término "conflictos individuales de seguridad social”, previsto en la actual Ley Federal del Trabajo, debiera sustituirse por el de "conflictos individuales derivados de un sistema básico de seguros sociales", pues este último es el que se ajusta a lo dispuesto en el artículo 899A del código obrero, cuyo único objeto es regular el reclamo de prestaciones en dinero y en especie derivadas de los diversos seguros que componen el régimen obligatorio del seguro social, y de aquellas que conforme a la Ley del Seguro Social y la Ley del Infonavit, con sus respectivos reglamentos, deban cubrir el Instituto Mexicano del Seguro Social, el Instituto del Fondo Nacional de la Vivienda para los Trabajadores y las administradoras de fondos para

15 Martínez Vivot, Julio, Elementos del derecho del trabajo y de la seguridad social, 5a. ed., Buenos Aires, Atrea, 1996, p. 612. 
el retiro, así como las que resulten aplicables en virtud de contratos colectivos de trabajo o contratos-ley, lo cual de ninguna manera refleja el alcance y contenido de la anhelada seguridad social.

\section{REGULACIÓN DE LOS PROCEDIMIENTOS ESPECIALES}

Los procedimientos especiales nacieron en la Ley Federal del Trabajo, publicada en el Diario Oficial de la Federación del 1o. de abril de 1970, debido a que si bien es cierto que todos los conflictos de trabajo deben resolverse en un periodo breve de tiempo, hay algunos cuya solución es particularmente urgente, ya sea por su menor cuantía, que generalmente significará una necesidad apremiante para el trabajador, o bien porque las causas que lo originan afectan la estabilidad o subsistencia de las empresas. ${ }^{16}$

En tales circunstancias, el capítulo VI, en sus artículos 782-788, de la Ley Federal del Trabajo de 1970 sujetó a la tramitación y resolución de los procedimientos especiales, a los conflictos que tenían por objeto el cobro de las siguientes prestaciones: ${ }^{17}$

- La aprobación del contrato de prestación de servicios de trabajadores mexicanos fuera de la República, contratados en territorio nacional (artículo 28, fracción III).

- Arrendamiento de habitaciones para los trabajadores (artículos 141; 145 , fracción IV, y 150).

- La determinación de la antigüedad del trabajador y la inconformidad contra ésta (artículo 158).

- Repatriación o traslado de trabajadores de los buques al lugar convenido (artículo 204, fracción IX).

- Repatriación de los trabajadores de los buques, pago de salarios hasta restituirlos al puerto de destino e indemnización por no proporcionarles otro trabajo, en caso de pérdida del buque por apresamiento o siniestro (artículo 209, fracción V).

16 Exposición de motivos de la Ley Federal del Trabajo, Diario de Debates de la Cámara de Diputados, 12 de diciembre de 1968, p. 29.

17 Ley Federal del Trabajo, Diario Oficial de la Federación, 1o. de abril de 1970, p. 91. 
- Trabajos encaminados a la recuperación de los restos del buque o de la carga, cubriendo a los trabajadores los salarios por los días que presten sus servicios, así como el pago de una bonificación adicional, si el valor de los objetos salvados excede del importe de los salarios, en proporción a los esfuerzos desarrollados y a los peligros arrostrados para el salvamento (artículo 210).

- Repatriación o traslado al lugar de contratación a los tripulantes de aeronaves que se destruyan o inutilicen fuera de ese lugar, garantizando el pago de salarios y gastos de viaje (artículo 236, fracción III).

- La determinación de la pérdida de la mayoría de los trabajadores en el contrato colectivo de trabajo y la titularidad de éste (artículo 389).

- La determinación de la administración del contrato-ley (artículo 418).

- Subsanar las omisiones del reglamento o revisar sus disposiciones contrarias a la Ley Federal del Trabajo y demás normas de índole laboral (artículo 424, fracción IV).

- Suspensión temporal de las relaciones de trabajo en una empresa o establecimiento, debido a las siguientes causas: fuerza mayor o caso fortuito no imputable al patrón; la incapacidad física, mental o muerte del empleador; la falta de materia prima, no imputable al patrón, y la falta de ministración por parte del Estado de las cantidades que se haya obligado a entregar a las empresas con las que hubiera contratado trabajos o servicios, siempre que aquéllas sean indispensables (artículo 427, fracciones I, II y VI).

- La terminación de las relaciones de trabajo por fuerza mayor o caso fortuito no imputable al patrón; la incapacidad física, mental o muerte del empleador; el agotamiento de la materia objeto de una industria extractiva, y el concurso o la quiebra legalmente declarado, si la autoridad competente o los acreedores resuelven el cierre definitivo de la empresa o la reducción definitiva de sus trabajos (artículo 434, fracciones I, III y V).

- La autorización por parte del patrón a la Junta de Conciliación y Arbitraje para la implantación de maquinaria o de procedimientos de trabajo nuevos que generen la reducción de personal, a falta de convenio (artículo 439).

- El pago de la indemnización ante la muerte del trabajador, a consecuencia de un riesgo de trabajo (artículo 503). 
- Resolver sobre la designación del médico, en caso de oposición de los trabajadores del que nombre el empleador (artículo 505).

- Los conflictos que tengan por objeto el cobro de prestaciones que no excedan el importe de tres meses de salario (artículo 892).

A los anteriores conflictos, la reforma procesal del 4 de enero de 1980, bajo el artículo 892 de la Ley Federal del Trabajo, adicionó como controversias que debían interponerse, tramitarse y resolverse como procedimientos especiales, a los siguientes: ${ }^{18}$

- Jornada excesiva por condiciones especialmente severas (artículo 5o., fracción III).

- La inserción del artículo 151 de la Ley Federal del Trabajo, que al regular al arrendamiento inmobiliario patronal sustituye a los artículos 141; 145, fracción IV, y 150 de la ley laboral de 1970.

- La obligación de capacitar y adiestrar a los trabajadores (artículo 153-X).

- La ocupación de plazas (artículo 159).

- El pago de gastos de traslado y menaje de casa a los trabajadores de tripulaciones aeronáuticas, cuando sean cambiados de su base de residencia (artículo 236, fracción II).

- El pago de la prima de antigüedad (artículo 162).

La actual Ley Federal del Trabajo, reformada mediante el Decreto publicado en el Diario Oficial de la Federación del 30 de noviembre de 2012, reconoce como sujetos a una tramitación especial, a todos los conflictos consignados en el citado artículo 892 de la ley laboral — producto de la reforma procesal del 4 de enero de 1980 — , pero de manera equívoca hace referencia al artículo 153, fracción X, que al ser inexistente, amerita la publicación de una fe de erratas para que se corrija que las controversias que se susciten con motivo de la aplicación del artículo 153-X se interpondrán, tramitarán y resolverán como procedimientos especiales,

Asimismo, la reforma laboral de 2012 introduce al capítulo XVIII la sección primera, a la cual denomina "Conflictos individuales de seguridad social”, a los que también reconoce como procedimientos especiales, ya que se

18 Decreto de reformas a la Ley Federal del Trabajo, Diario Oficial de la Federación, 4 de enero de 1980, p. 14. 
requiere de "un procedimiento sumario para tramitar los conflictos suscitados con motivo del otorgamiento de prestaciones de seguridad social, aportaciones de vivienda y prestaciones derivadas del sistema de ahorro para el retiro".

Con la anterior medida se pretende que los conflictos individuales de seguridad social

...se resuelvan con mayor celeridad, para lo cual, se establecen reglas de competencia de las Juntas Especiales de la Federal de Conciliación y Arbitraje; requisitos que deben contener las demandas de este tipo de conflictos; elementos que deben contener los dictámenes médicos en los casos de riesgos de trabajo y reglas para el desahogo de esta prueba; se propone que los peritos médicos se encuentren registrados ante la Junta Federal de Conciliación y Arbitraje. ${ }^{19}$

\section{ASPECTO PROCESAL DE LOS CONFLICTOS INDIVIDUALES DE SEGURIDAD SOCIAL}

De acuerdo con el artículo 899-A de la Ley Federal del Trabajo, los conflictos individuales de seguridad social tienen por objeto reclamar el otorgamiento de prestaciones en dinero o en especie derivadas de los diversos seguros que componen el régimen obligatorio del seguro social, organizado y administrado por el Instituto Mexicano del Seguro Social, y de aquellas que conforme a la Ley del Seguro Social y la Ley del Instituto del Fondo Nacional de la Vivienda para los Trabajadores deban cubrir el Instituto del Fondo Nacional de la Vivienda para los Trabajadores y las administradoras de fondos para el retiro, así como las que resulten aplicables en virtud de contratos colectivos de trabajo o contratos-ley que contengan beneficios en materia de seguridad social.

Al ser tramitados los conflictos individuales de seguridad social como procedimientos especiales, éstos constituyen la expresión más rotunda de la concentración procesal, ya que en la primera audiencia —única en términos generales - se celebran las etapas de conciliación, demanda y excepciones,

19 Exposición de motivos del Decreto que reforma, adiciona y deroga diversas disposiciones de la Ley Federal del Trabajo, Diario de Debates de la Cámara de Diputados, 4 de septiembre de 2012, p. 3. 
pruebas y resolución; todo ello, al decir de la ley, se realizará en un plazo de quince días, ${ }^{20}$ contados a partir de la presentación del escrito inicial de demanda, que de acuerdo con el artículo 899-C de la Ley Federal del Trabajo, deberá contener:

- Nombre, domicilio, fecha de nacimiento del promovente.

- La expresión de las pretensiones y de los hechos.

- El nombre y el domicilio de las empresas en las que ha laborado el actor; puestos desempeñados y actividades desarrollados; antigüedad; número de seguridad social; cotizaciones al régimen de seguridad social; unidad de medicina familiar asignada.

- Ante el reclamo de prestaciones derivadas de riesgos de trabajo o enfermedades generales debe designarse un perito médico y un perito técnico, cuando estos últimos sean necesarios para el esclarecimiento de los hechos. Únicamente, los peritos médicos, de conformidad con los artículos 899-F y décimo tercero transitorio de la Ley Federal del Trabajo, deberán estar inscritos en el registro de la Junta Federal de Conciliación y Arbitraje para que proceda la recepción de los dictámenes que rindan. ${ }^{21}$

Asimismo, el promovente deberá anexar las pruebas que juzgue convenientes para acreditar sus pretensiones, e incorporará los documentos siguientes:

- Aquellos que acrediten la personalidad.

- El último estado de la cuenta individual de ahorro para el retiro, constancia expedida por el IMSS de otorgamiento o negativa de pensión, o constancia de otorgamiento o negativa de crédito para vivienda.

20 Buen Lozano, Néstor de, Derecho procesal del trabajo, 20a. ed., México, Porrúa, 2014, p. 647.

21 Se considera que al imponerse a los peritos médicos la obtención de un registro para que estén en posibilidad de rendir sus dictámenes, el cual no se exige en el caso de los peritos técnicos, contables, caligráficos, grafométricos, en trabajo social, avalúos e inglés, quienes también se encuentran adscritos a la Secretaría Auxiliar de Peritajes y Diligencias de la Junta Federal de Conciliación y Arbitraje, contraviene lo dispuesto en el artículo 1o. de la Constitución federal, ya que al imponerse mayores requisitos a los médicos que al resto de los profesionistas que auxilian a la autoridad laboral en la toma de decisiones, se está brindando un trato diferenciado, el cual anula la libertad de trabajo prevista en el artículo 5o. constitucional, cuando el perito médico carece del correspondiente registro, a pesar de estar legalmente autorizado para el ejercicio de su profesión — tal y como lo acreditará en la etapa de desahogo de la prueba pericial, con la exhibición de su título y cédula profesional expedidos por la autoridad competente- y no encontrarse dentro de las limitaciones impuestas a la libertad de trabajo previstas en los artículos 5o. constitucional y 4o. de la Ley Federal del Trabajo. 
- Los documentos expedidos por los patrones, el Instituto Mexicano del Seguro Social, el Instituto del Fondo Nacional de la Vivienda para los Trabajadores y la administradora de fondos para el retiro correspondiente, o, en su caso, el acuse de recibo de la solicitud de los mismos, y, en general, aquella información necesaria que garantice la sustanciación del procedimiento con apego al principio de inmediatez.

- Las copias necesarias de la demanda y sus anexos.

El escrito inicial de demanda se interpone ante Oficialía de Partes de la Junta Federal de Conciliación y Arbitraje, quien la turnará a Control Procesal para que abra expediente del caso, así como para que agregue y radique el escrito inicial de demanda con los documentos y pruebas exhibidos.

La autoridad laboral en el auto de radicación establece el día y hora en que tendrá verificativo la audiencia de conciliación, demanda y excepciones, pruebas y resolución, la que deberá efectuarse dentro de los quince días hábiles siguientes a la fecha en que se haya presentado la demanda, quedando apercibidas las partes que de no concurrir a la audiencia, se les tendrá por inconformes con todo arreglo conciliatorio; por reproducido el escrito inicial de demanda, $y$, en su caso, por ofrecidas las pruebas que hubiere acompañado, ante la incomparecencia del promovente. Por el contrario, la inasistencia del demandado a la audiencia dará lugar a la admisión de las peticiones de la parte actora, salvo que sean contrarias a lo dispuesto en la ley.

Igualmente, en el auto de radicación se apercibe a las partes para que con fundamento en el artículo 739 de la Ley Federal del Trabajo señalen domicilio para oír y recibir notificaciones, pues de no hacerlo, las subsecuentes notificaciones, aun las de carácter personal, surtirán sus efectos por medio del Boletín Laboral.

Una vez firmado el auto de radicación por los representantes del trabajo, del capital y del gobierno, así como por el secretario de acuerdos, el expediente laboral es turnado al actuario, para que en términos de los artículos 742 , fracción II, y 893 del código de trabajo, notifique a las partes el acuerdo de radicación. En el caso de la parte señalada como demandada, el actuario deberá entregarle copia de la demanda interpuesta para que esté en posibilidad de dar contestación a la misma.

La audiencia de conciliación, demanda y excepciones, pruebas y resolución únicamente tendrá verificativo cuando a las partes se les notifique su celebra- 
ción con diez días de anticipación. Por disposición del artículo 895 de la Ley Federal del Trabajo, una vez que los comparecientes se acrediten como abogados, licenciados en derecho con cédula profesional o personas que cuenten con carta de pasante vigente expedida por la autoridad competente para ejercer dicha profesión, y estando legalmente integrada la Junta, el representante de gobierno (auxiliar) abrirá la audiencia en su etapa de conciliación.

La reforma laboral de 2012 incorpora

el principio de la conciliación en el proceso laboral. De esta manera, durante todo el procedimiento y hasta antes de dictarse el laudo, las Juntas intentarían que las partes resuelvan los conflictos mediante la conciliación. En complemento a esta medida, se crea la figura de los funcionarios conciliadores, como parte del personal jurídico de las Juntas. ${ }^{22}$

Así, en la etapa de conciliación —a la que podrán comparecer personalmente las partes asistidos por sus abogados, asesores o apoderados legales_-, ${ }^{23}$ la autoridad laboral por conducto del funcionario conciliador o de su personal jurídico intervendrá para la celebración de pláticas entre las partes comparecientes, y las exhortará para que procuren llegar a un arreglo, proponiéndoles opciones de soluciones justas y equitativas que, a su juicio, sean adecuadas para dar por terminada la controversia planteada.

En el caso de los representantes del Instituto Mexicano del Seguro Social, del Instituto del Fondo Nacional de la Vivienda para los Trabajadores y las administradoras de fondos para el retiro es necesario que tengan facultades para asumir una solución conciliatoria que obligue a su representado. La celebración de la etapa de conciliación produce los efectos siguientes:

- La obtención de un acuerdo conciliatorio que dará por terminado el conflicto individual de seguridad social, cuando las partes elaboren un convenio y éste sea aprobado por la Junta, produciendo todos los efectos jurídicos inherentes a un laudo.

22 Exposición de motivos del Decreto que reforma, adiciona y deroga diversas disposiciones de la Ley Federal del Trabajo, Diario de Debates..., cit., p. 35.

23 La reforma laboral de 2012 modificó la fracción I del artículo 876 de la Ley Federal del Trabajo, que prohibía que en la etapa de conciliación las partes comparecieran asistidos de abogados patronos, asesores o apoderados. 
- Diferir la audiencia de conciliación, demanda y excepciones, pruebas y resolución, cuando las partes estén en posibilidad de sostener pláticas conciliatorias tendientes a dar por terminado el conflicto individual de seguridad social. En este caso, la Junta suspenderá por una sola vez la audiencia, pero deberá señalar nuevo día y hora para su celebración, a fin de que las partes le comuniquen el resultado de las pláticas sostenidas.

- La falta de un acuerdo conciliatorio. En este último supuesto, la Junta tendrá por celebrada y cerrada la etapa conciliatoria, procediéndose con la continuación de la audiencia en su siguiente etapa: demanda y excepciones, pruebas y resolución.

Abierta la etapa de demanda y excepciones, en primer lugar se concederá el uso de la voz a la parte actora para que proceda a ratificar o ampliar su demanda. Acto seguido, se le dará el uso de la voz a los apoderados del Instituto Mexicano del Seguro Social, el Instituto del Fondo Nacional de la Vivienda para los Trabajadores y la correspondiente administradora de fondos para el retiro para que contesten la demanda y ofrezcan aquellas pruebas que justifiquen sus excepciones y defensas, así como para objetar las probanzas ofrecidas por la parte actora.

Para concluir esta etapa, nuevamente la parte actora tendrá el uso de la voz para que replique y objete las pruebas ofrecidas por los organismos de seguridad social y la administradora de fondos para el retiro. Por su parte, la Junta dictará el correspondiente acuerdo, en el que resolverá los aspectos siguientes:

- El reconocimiento de personalidad de los comparecientes.

- La admisión de la demanda y la contestación.

- Las objeciones formuladas por las partes.

- La admisión o desechamiento de las probanzas ofrecidas por las partes. Únicamente se admitirán aquellas pruebas que se hayan ofrecido conforme a derecho; tengan relación con la litis planteada; no sean contrarias a la moral, y se refieran a hechos controvertidos, en términos del capítulo XII de la Ley Federal del Trabajo.

- El desahogo de los medios probatorios que lo ameriten. 
Finalmente, y de acuerdo con la fracción IV del artículo 895 de Ley Federal del Trabajo, se dispone que concluida la recepción de pruebas, la JFCA escuchará los alegatos y dictará resolución.

Con relación a la fracción IV del artículo 895 de la ley laboral, se considera necesaria su reforma, ya que debe sustituirse el término "recepción" por el de "desahogo", pues en el caso de las pruebas confesional, documental — cuando se objeta en cuanto a su autenticidad, literalidad y firma-, testimonial, pericial, ${ }^{24}$ de inspección, fotografías, cintas cinematográficas, registros dactiloscópicos, grabaciones de audio, de video o las distintas tecnologías de la información y la comunicación, no es suficiente su recepción y admisión por parte de la Junta, sino que dichos medios probatorios requieren de un desahogo especial, el cual involucra una serie de actuaciones a cargo de las partes y la autoridad que hacen imposible que tenga lugar la formulación de los alegatos, si antes no se ha cerrado la etapa probatoria en sus fases de "ofrecimiento", "recepción" y, finalmente, "desahogo", que son tres aspectos totalmente diferentes que llevan una secuencia lógica dentro de todo procedimiento.

Una vez que el secretario de acuerdos de la JFCA certifique que no quedan pruebas pendientes por desahogar, procederá a dar vista a las partes — concediéndoles un término de tres días - para que expresen su conformidad con dicha certificación, bajo el apercibimiento de que si transcurrido el término señalado no lo hicieren y hubieren pruebas por desahogar, se les tendrá por desistidos de las mismas para todos los efectos legales, decretándose de oficio el cierre de la instrucción por parte del representante de gobierno y la formulación del proyecto de resolución a cargo del auxiliar dictaminador.

Por el contrario, cuando las partes al contestar la vista acrediten que alguna prueba ofrecida y admitida no se desahogó, la Junta — dentro de los ocho días siguientes - ordenará su desahogo, pues al concluir éste, dentro de las veinticuatro horas siguientes, las partes formularán o renunciarán a la expresión de sus alegatos y, posteriormente, el representante de gobierno decretará el cierre de la instrucción, además de turnar los autos con el auxiliar dictaminador para que formule por escrito el proyecto de laudo, contemplando los siguientes elementos:

24 Dentro de los treinta días siguientes a la celebración de la conciliación, demanda y excepciones, pruebas y resolución, la Junta señalará día y hora para la audiencia en que se recibirán los dictámenes periciales con citación de las partes, con el apercibimiento de que el no comparecer dará por perdido su derecho para formular repreguntas u observaciones. 
- Lugar, fecha, Junta que lo pronuncie, y los nombres y domicilios de las partes y de sus representantes.

- Extracto de la demanda y su contestación; réplica y contrarréplica, y, en su caso, de la reconvención y contestación a la misma, que deberá contener con claridad y concisión las peticiones de las partes y los hechos controvertidos.

- Enumeración de las pruebas admitidas y desahogadas, así como su apreciación en conciencia, señalando los hechos que deban considerarse probados.

- Extracto de los alegatos.

- Las razones legales o de equidad, así como la jurisprudencia y la doctrina que les sirva de fundamento.

- Los puntos resolutivos.

Normalmente, el lugar y la fecha de emisión; la autoridad que lo pronuncia; los nombres de las partes, y el número de expediente constituyen los datos que la Junta establece en el rubro y al inicio del documento denominado "proyecto de resolución".

En lo concerniente al extracto de la demanda, contestación, réplica, contrarréplica, reconvención y contestación a la misma (de ser planteadas), la enumeración de las pruebas admitidas y desahogadas, así como un extracto de los alegatos (si fueron formulados por las partes), constituyen lo que se conoce con el nombre de resultandos. Es necesario que el proyecto de resolución y el laudo sean claros, precisos y congruentes con la demanda, contestación y demás pretensiones deducidas en el juicio, pues de lo contrario, procederá la interposición del amparo directo, ya que la autoridad laboral no puede referirse a otros hechos que a los alegados y probados por las partes.

Por su parte, el establecimiento de la competencia del órgano que emite la resolución; la fijación de la litis; el estudio y análisis de las acciones intentadas; las excepciones y defensas opuestas; la valoración de las pruebas ofertadas por las partes; las razones legales o de equidad, así como la jurisprudencia y la doctrina que le sirvan de fundamento a la autoridad laboral para emitir el proyecto de resolución, forman parte de los considerandos, pues si bien es cierto que el citado proyecto elevado a la categoría de laudo se dicta a verdad sabida 
y buena fe guardada, apreciando los hechos en conciencia, sin necesidad de sujetarse a reglas o formulismos sobre la estimación de las pruebas, ello no exime a la Junta de expresar los motivos y los fundamentos legales en que se apoya para resolver el conflicto individual de seguridad social interpuesto.

La última parte del proyecto son los puntos resolutivos, en los que de acuerdo con los considerados, la autoridad laboral condena, absuelve o parcialmente condena y absuelve a la parte demandada (resolución mixta). Es indispensable que cuando se condene al pago de prestaciones económicas, se establezca el salario que sirvió de base para realizar la cuantificación de las mismas, pues sólo por excepción podrá ordenarse la apertura de incidente de liquidación en la resolución que se pronuncie.

Del proyecto de laudo, de acuerdo con el artículo 886 de la Ley Federal del Trabajo, se entregará copia a cada uno de los integrantes de la Junta, a fin de que dentro de los cinco días hábiles siguientes a aquel en que se hubiere recibido la copia del proyecto, cualquiera de ellos pueda solicitar que se practiquen las diligencias que juzguen convenientes para el esclarecimiento de la verdad. Concluido el citado término o, en su caso, desahogadas las diligencias que en él se hubieran solicitado, el presidente de la Junta citará a los miembros de la misma para discutir el proyecto.

La discusión y la votación del proyecto de laudo se llevarán a cabo en sesión de la Junta, y una vez que el secretario de acuerdos haya certificado la presencia de los participantes que concurran a la votación, dará lectura al proyecto de resolución, a los alegatos de las partes y a las observaciones formuladas por las partes. Por su parte, el presidente de la Junta pondrá a discusión el negocio con el resultado de las diligencias practicadas, y una vez terminada la discusión, se procederá a la votación.

De aprobarse el proyecto de resolución, sin adiciones ni modificaciones, se elevará a la categoría de laudo. Por el contrario, si al proyecto se le hicieran modificaciones o adiciones, se ordenará al auxiliar dictaminador que inmediatamente redacte el laudo de conformidad con lo aprobado.

Emitido el laudo, el secretario de acuerdos procederá a su engrose; esto es, adicionarlo al expediente correspondiente en forma oficial (cosido, sellado y foliado $)^{25}$ para proceder a firmarlo y a recabar en él las firmas de los miem-

25 Tenopala Mendizábal, Sergio, Derecho procesal del trabajo, 3a. ed., México, Porrúa, 2012, p. 632. 
bros de la Junta que votaron en el negocio, a fin de que pueda ser turnado al actuario para su notificación personal a las partes, en términos de la fracción VIII del artículo 742 del Código de Trabajo.

La Suprema Corte de Justicia de la Nación ha sostenido que la falta de firma del laudo por parte de alguno de los integrantes de un tribunal de trabajo o del secretario de acuerdos trae consigo su nulidad, sin que para el caso pueda hacerse pronunciamiento sobre su constitucionalidad, pues no debe surtir efecto jurídico alguno, ya que de lo contrario se estaría subsanando el vicio de origen. Conforme a ello, el órgano de control constitucional, sin necesidad de que en la demanda de amparo correspondiente se expresen conceptos de violación sobre tal aspecto e independientemente de quién la promueva, deberá declarar la nulidad del laudo y ordenarle al tribunal que lo emitió subsanar tal formalidad. ${ }^{26}$

26 Tesis 2a./J. 147/2007, Semanario Judicial de la Federación y su Gaceta, Novena Época, t. XXXIII, abril de 2011, p. 518. 


\section{Cuadro 1}

\section{PROCEDIMIENTO ESPECIAL EN LOS CONFLICTOS INDIVIDUALES DE SEGURIDAD SOCIAL ${ }^{27}$}

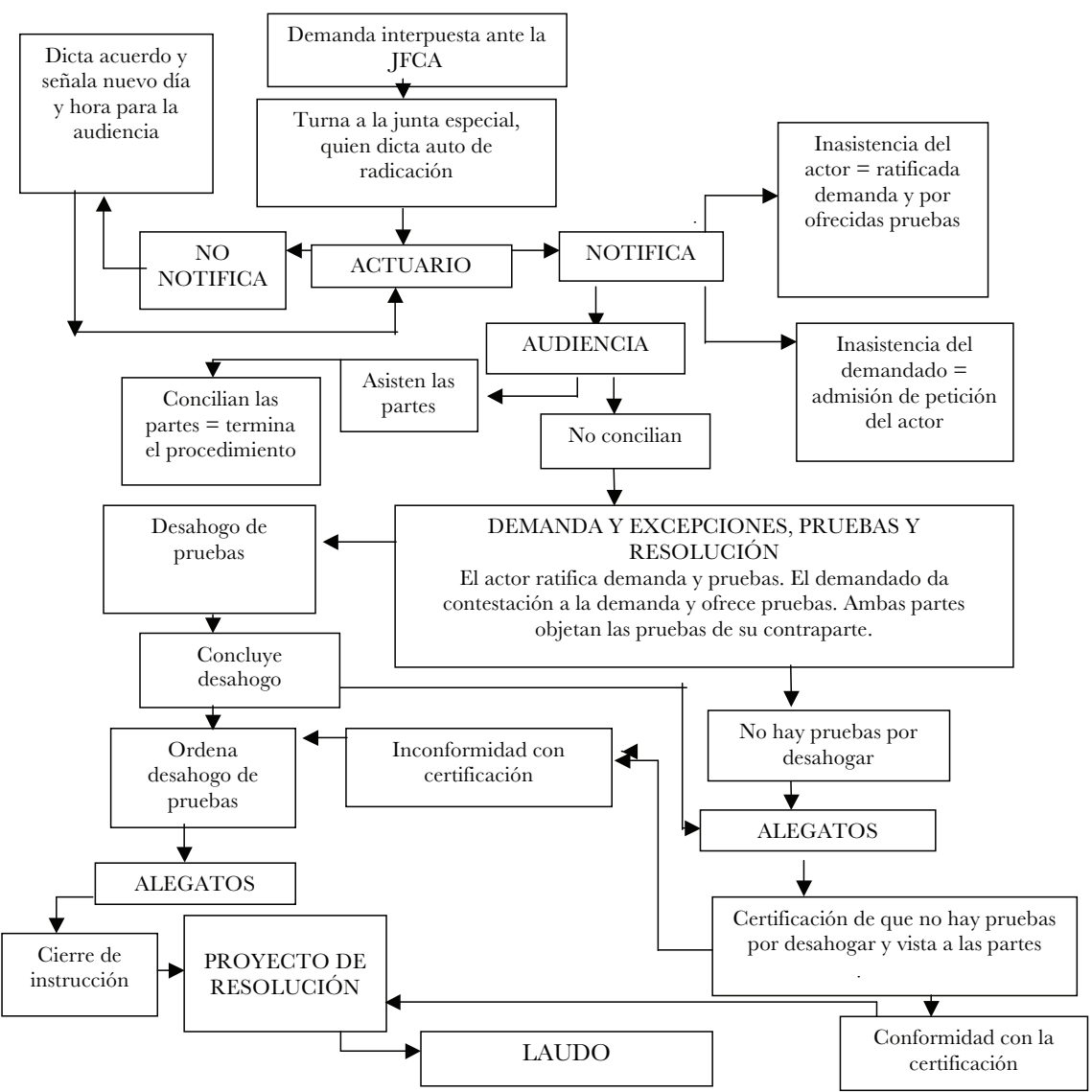

27 Elaborado con fundamento en los artículos 893 al 899 y 899-A al 899-G de la Ley Federal del Trabajo, http://mmw.diputados.gob.mx/LeyesBiblio/index.htm, consultada el 14 de diciembre de 2014. 


\section{PROBLEMÁTICA QUE PRESENTAN LOS CONFLICTOS INDIVIDUALES DE SEGURIDAD SOCIAL}

De acuerdo con las reformas efectuadas a la Ley Federal del Trabajo y a las leyes de seguridad social — con una marcada tendencia a la privatización de los servicios que en principio son responsabilidad del Estado-, la problemática de los conflictos individuales de seguridad social se concentra en dos aspectos fundamentales, los cuales son:

- Incompetencia de la autoridad que los resuelve.

- Su indebida regulación en la Ley Federal del Trabajo.

Conforme a lo dispuesto en el apartado A, fracción XX, del artículo 123 constitucional, las diferencias o los conflictos entre el capital y el trabajo se sujetarán a la decisión de una junta de conciliación y arbitraje, formada por igual número de representantes de los obreros y de los patronos, así como un representante del gobierno.

En este mismo tenor, el artículo 604 de la Ley Federal del Trabajo preceptúa que el conocimiento y la resolución de los conflictos de trabajo que se susciten entre trabajadores y patrones, sólo entre aquéllos o sólo entre éstos, derivados de las relaciones de trabajo o de hechos relacionados con ellas, corresponde a la Junta Federal de Conciliación y Arbitraje, que en el ámbito de su competencia, en términos del artículo 606 del código obrero, funcionará en Pleno o en juntas especiales.

Primeramente, por lo que hace al Pleno de la JFCA, se integra con el presidente de la Junta, los representantes de los trabajadores y los representantes de los patrones ante las juntas especiales del Distrito Federal. En cambio, las juntas especiales, por disposición del artículo 609 de la ley laboral, se integrarán con el presidente de la Junta, cuando se trate de conflictos colectivos, o con el presidente de la junta especial en los demás casos, y los respectivos representantes de los trabajadores y de los patrones.

Lo anterior evidencia que el personal que forma parte de la Junta Federal de Conciliación y Arbitraje, funcionando en Pleno o en juntas especiales, no corresponde con los elementos subjetivos que intervienen en los conflictos individuales de seguridad regulados en los artículos 899-A al 899-G de la Ley Federal del Trabajo, los cuales son: 
- Los organismos denominados Instituto Mexicano del Seguro Social e Instituto del Fondo Nacional de la Vivienda para los Trabajadores.

- Los asegurados. Bajo esta denominación se incluyen a los que se encuentran inscritos en el régimen obligatorio del seguro social, aquellos que de manera voluntaria se incorporen a dicho régimen y los que se rijan por contratos colectivos de trabajo o contratos-ley que contengan beneficios en materia de seguros sociales.

- Los pensionados.

- Los beneficiarios de los asegurados y pensionados.

- Los patrones y sujetos obligados.

- Las distintas administradoras de fondos para el retiro.

- Las sociedades de inversión especializadas.

- Las compañías de seguros con las que las afores deben contratar los seguros de sobrevivencia.

La ausencia de los referidos sujetos en la integración de la Junta Federal de Conciliación y Arbitraje repercute, en la mayoría de los casos, en la falta de conocimiento de la naturaleza, carácter y teleología de las instituciones contenidas en la leyes del seguro social de $1973^{28}$ y 1997 (actualmente vigente), la Ley de los Sistemas de Ahorro para el Retiro, la Ley del Infonavit y sus múltiples reglamentos, así como los acuerdos emitidos por el Consejo Técnico del Instituto Mexicano del Seguro Social.

A lo anterior se adiciona que por disposición de los artículos 626, fracción III; 627, fracción III; 627-B, fracción III, y 628, fracción III, de la Ley Federal del Trabajo, para ocupar el cargo de actuario, secretario, conciliador y auxiliar de una junta especial es necesario tener título de abogado o licenciado en derecho, y haber distinguido en estudios de derecho del trabajo, siendo además necesario, en el caso del funcionario conciliador y del auxiliar, contar con dos $\mathrm{y}$ tres años de ejercicio profesional en materia laboral, respectivamente.

28 Por disposición de los artículos tercero, cuarto y undécimo transitorios de la actual Ley del Seguro Social, los asegurados inscritos con anterioridad a la fecha de entrada en vigor de la actual Ley del Seguro Social, así como sus beneficiarios, al momento de cumplirse, en términos de la Ley del Seguro Social de 1973, que se deroga, los supuestos legales o el siniestro respectivo para el disfrute de cualquiera de las pensiones, podrán optar por acogerse al beneficio de este último ordenamiento o al esquema de pensiones establecido en la actual Ley del Seguro Social. 
Por su parte, en el caso de presidentes y secretarios generales, conforme a los artículos 629 y 630 del código laboral, es necesario tener título de abogado o licenciado en derecho, acreditar cinco años de ejercicio profesional en materia laboral, posteriores a la obtención del correspondiente título, y haberse distinguido en estudios sobre derecho del trabajo.

Lamentablemente, el conocimiento teórico-práctico del derecho laboral que se exige al personal encargado de tramitar y resolver los conflictos individuales de seguridad social es insuficiente para solucionar las múltiples y disímiles controversias que plantean los asegurados, los pensionados y los beneficiarios contra el Instituto Mexicano del Seguro Social, las administradoras de fondos para el retiro y el Instituto del Fondo Nacional de la Vivienda para los Trabajadores.

Ante las marcadas diferencias que existen entre las prestaciones de índole laboral y las derivadas de los seguros sociales, los requisitos para su otorgamiento; la manera en que prescriben, si no se demanda su pago oportunamente, así como los sujetos encargados de financiarlas y otorgarlas, amerita la existencia de conocimientos especializados en el derecho de la seguridad social, el derecho fiscal, el derecho bancario y bursátil, indispensables todos ellos para comprender el nuevo paradigma que impera en el sistema de seguros básicos ante la hegemonía de las distintas administradoras de fondos para el retiro y las sociedades de inversión especializadas de fondos para el retiro, cuya organización, funcionamiento y actual problemática se desconocen por los miembros que integran la Junta Federal de Conciliación y Arbitraje.

Consecuentemente, ante la falta de regulación de los denominados conflictos individuales de seguridad social en la norma constitucional, la Junta Federal de Conciliación y Arbitraje carece de competencia para tramitarlos y resolverlos, sin que en contra pueda admitirse el argumento de que los artículos 899-A de la Ley Federal del Trabajo, 295 de la Ley del Seguro Social y 53 de la Ley del Infonavit se la otorguen, pues atendiendo al principio de jerarquía normativa, el cual encuentra especial sustento en la supremacía de la Constitución sobre el mandato de una ley reglamentaria, como en este caso lo son la Ley Federal del Trabajo, la Ley del Seguro Social y la Ley del Infonavit, debe prevaler el artículo 123 constitucional, que sólo otorga facultades a la Junta Federal de Conciliación y Arbitraje para resolver los conflictos entre el capital y el trabajo, los cuales no tienen ninguna relación con los conflictos individuales de seguridad social, cuyas principales características son: 
- Son controversias que surgen entre los organismos denominados de seguridad social y los asegurados, los pensionados, los beneficiarios, los patrones y los demás sujetos obligados. A partir del 1o. de julio de 1997, fecha en que entró en vigor la actual Ley del Seguro Social, es posible la existencia de controversias entre los referidos sujetos y las administradoras de fondos para el retiro y sus sociedades de inversión.

- Entre los organismos denominados de seguridad social y los asegurados o pensionados existe una relación de órgano asegurador-asegurado.

- A los organismos de seguros sociales les corresponde otorgar y cubrir las prestaciones, tanto en dinero como en especie, a aquellos sujetos que las leyes establezcan como beneficiarios de las mismas y aporten para su financiamiento.

- Al tener los patrones y sujetos obligados la obligación de retener y enterar las cuotas obrero-patronales a los institutos de seguros sociales, la relación que existe entre ambas partes es de índole tributaria.

- Los organismos de seguros sociales son la contraparte de los asegurados, los pensionados y los beneficiarios, en virtud de la figura jurídica de la subrogación, la cual deriva del correspondiente pago de cuotas empleadas para el financiamiento de los seguros sociales que se otorguen.

- Se mantiene la desigualdad de las partes.

- Este tipo de conflictos versan sobre derechos de orden individual, pues la propia naturaleza jurídica de los sistemas de seguros sociales crea derechos para cada asegurado o pensionado, directamente proporcionales con las cotizaciones pagadas.

- Tienen por objeto reclamar prestaciones económicas y en especie derivadas de un sistema de seguros sociales previstas en la ley que los regula, los contratos colectivos de trabajo o en los contratos-ley.

- Son de orden público.

- Surgen a pesar de que se haya concluido la relación laboral o ésta sea inexistente, siendo un claro ejemplo de esto último los individuos que desempeñan una actividad económica en talleres familiares o de manera independiente, como acontece en el caso de los profesionales, de los comerciantes en pequeño, de los artesanos y de los sujetos agrarios.

- Responden a condiciones de orden económico. 
- Son dinámicos, lo cual obedece, en gran medida, al reemplazo del sistema de pensiones públicas por el de capitalización individual y las modificaciones en torno a los requisitos para acceder a las prestaciones derivadas de los privatizados "seguros sociales".

Finalmente, por lo que respecta a la regulación de los conflictos individuales de seguridad social en la Ley Federal del Trabajo, es necesario remitirnos al artículo 1o. de este ordenamiento, cuyo texto dispone: "La presente Ley es de observancia general en toda la República y rige las relaciones de trabajo comprendidas en el artículo 123, Apartado A, de la Constitución”.

De lo anterior, se sigue que el ordenamiento especializado en regular las relaciones individuales y colectivas de naturaleza laboral es la Ley Federal del Trabajo, en la que se plasman una serie de derechos y obligaciones a cargo de los dos factores que intervienen en el proceso productivo: los patrones y los trabajadores, a quienes corresponde el derecho de acudir ante la autoridad laboral para exigir el respeto, el cumplimiento y la exacta observancia de las disposiciones contenidos en el código obrero.

En el caso de los conflictos individuales de seguridad social, entre los asegurados o pensionados, así como sus respectivos beneficiarios, y el Instituto Mexicano del Seguro Social o el Instituto del Fondo Nacional de la Vivienda para los Trabajadores no existe una relación obrero-patronal, sino de órgano asegurador-asegurado, ya que corre a cargo de dichos organismos de seguros sociales el otorgar y cubrir las prestaciones en dinero y en especie contempladas en la Ley del Seguro Social o en la Ley del Infonavit, a todos aquellos que aporten para su financiamiento.

Tratándose de los patrones y sujetos obligados, la relación tiene un carácter tributario, al tener el empleador la obligación de retener y enterar las cuotas obrero-patronales al Instituto Mexicano del Seguro Social, así como la de aportar y practicar a los asegurados los descuentos, que serán enterados al Instituto del Fondo Nacional de la Vivienda para los Trabajadores, pues al poseer ambos organismos el carácter de fiscales, por disposición de los artículos 5o. de la Ley del Seguro Social y 30 de la Ley del Infonavit, cuentan con facultades para determinar los créditos a cargo del sujeto obligado; establecer las bases para la liquidación de cuotas, recargos, así como sus accesorios; fijarlos en cantidad líquida; cobrarlos y percibirlos. 
De lo anterior se desprende que la Ley Federal del Trabajo no es el ordenamiento que debe regular la interposición, tramitación y resolución de los conflictos individuales de seguridad social, ya que su ámbito de aplicación se constriñe, por mandato de su artículo 1o., a regir las relaciones de trabajo comprendidas en el artículo 123, apartado A, de la Constitución, las cuales son inexistentes en el caso de los sistemas de seguros sociales dirigidos por el Instituto Mexicano del Seguro Social y el Instituto del Fondo Nacional de la Vivienda para los Trabajadores, cuyo financiamiento corre a cargo del Estado, los asegurados y los patrones o sujetos obligados (tripartismo).

Resulta absurdo que en atención a la estrecha vinculación que existe entre el derecho de la seguridad social y el derecho laboral por razones de origen, al encontrar ambos su fundamento en el apartado A del artículo 123 constitucional y ser partes integrantes del derecho social, se dote de competencia a la Junta Federal de Conciliación y Arbitraje para tramitar y resolver los denominados conflictos individuales de seguridad social, cuando el sistema de seguros sociales es autónomo, y su existencia, marco legal, administración y financiamiento se encuentran regulados dentro de la Ley del Seguro Social y sus normas reglamentarias, cuya referencia y aplicación a la Ley Federal del Trabajo sólo debiera hacerse de manera supletoria; por ejemplo, en lo no previsto en las normas especializadas.

Es necesaria la creación de normas de tipo adjetivo en las leyes de seguridad social, en las que se reglamenten procedimientos adecuados para la tramitación de las controversias que se susciten en materia de seguros sociales, los órganos especializados en su resolución y los mecanismos apropiados para la solución de las controversias planteadas por los asegurados, los pensionados, los beneficiarios, los patrones y los sujetos obligados, pues las críticas realizadas a la Junta Federal de Conciliación y Arbitraje bien pueden ser aplicables al Tribunal Federal de Justicia Fiscal y Administrativa.

Que nos quede claro, de una vez por todas, que tanto el derecho laboral como el derecho fiscal difieren del derecho de la seguridad social, ya que tienen instituciones jurídicas, marcos normativos, una evolución y un desarrollo diferentes, y en el particular caso del derecho fiscal, éste responde a principios disímiles de los que guían al derecho de la seguridad social, el cual se encuentra adscrito al derecho social, con todo lo que ello implica y lleva aparejado. 


\section{FUENTES DE INFORMACIÓN}

\section{Libros}

AlEXY, Robert, Teoría de los derechos fundamentales, 3a. reimp., trad. de Ernesto Garzón Valdés, Madrid, Centro de Estudios Políticos y Constitucionales, 2002.

Almansa Pastor, José Manuel, Derecho de la seguridad social, Madrid, Tecnos, 1973.

Alonso Olea, Manuel, Instituciones de seguridad social, 7a. ed., Madrid, Centro de Estudios Constitucionales, 1979.

Ávila SAlCEDo, Luis Fernando, La seguridad social y el Instituto Mexicano del Seguro Social, México, Porrúa, 2007.

BRICEÑo RuIZ, Alberto, Derecho mexicano de los seguros sociales, México, Harla, 1987.

Derecho de la seguridad social, México, Oxford, 2010.

Buen Lozano, Néstor de, Derecho procesal del trabajo, 20a. ed., México, Porrúa, 2014.

CÁzares GarcíA, Gustavo, Derecho de la seguridad social, 3a. ed., México, Porrúa, 2014.

FERnÁndez RuIZ, Silvestre, Prestaciones y servicios del IMSS. Cálculo y procedimientos, 3a. ed., México, Trillas, 1998.

FERRARI, Francisco de, Los principios de la seguridad social, Uruguay, Biblioteca de Publicaciones Oficiales de la Facultad de Derecho y Ciencias Sociales de la Universidad de Montevideo, 1955.

GARcía Cruz, Miguel, La seguridad social en México. Bases, evolución, importancia económica, social, politica y cultural, México, B. Costa-Amic, 1998.

GAVARA DE CARA, Juan Carlos, La dimensión objetiva de los derechos sociales, Barcelona, Bosch, 2001.

Instituto Mexicano del Seguro Social, Glosario de Términos Técnico-Administrativos de Uso Frecuente en el Instituto Mexicano del Seguro Social, 12a. ed., México, IMSS, 2008. 
MARTÍNEZ VIVOT, Julio, Elementos del derecho del trabajo y de la seguridad social, 5a. ed., Buenos Aires, Atrea, 1996.

NETTER, F., La seguridad social y sus principios, trad. de Julio Arteaga, México, Instituto Mexicano del Seguro Social, 1982.

ORGANIZACIÓN INTERNACIONAL DEL TRABAJO, Introducción a la seguridad social, 3a. ed., Ginebra, OIT, 1984.

PÉREZ LEÑERO, José, Fundamentos de la seguridad social, Madrid, Aguilar, 1956.

RICHARDSON, J. Henry, La seguridad social aspectos económicos y financieros, Buenos Aires, Victor Lerú, 1962.

RouZAUT, Adolfo, Fundamento constitucional de la seguridad social, Argentina, Instituto de Derecho Constitucional, 1962.

RuIZ MORENO, Ángel Guillermo, La impugnación legal de los actos definitivos del seguro social en México, México, Porrúa, 2012.

—, Nuevo derecho de la seguridad social, 14a. ed., México, Porrúa, 2013.

Tenopala MendizÁBal, Sergio, Derecho procesal del trabajo, 3a. ed., México, Porrúa, 2012.

\section{Leyes y publicaciones oficiales}

Ley Federal del Trabajo, Diario Oficial de la Federación, 1o. de abril de 1970.

Constitución Política de los Estados Unidos Mexicanos, http:/ / www.diputados. gob.mx/LeyesBiblio/ref/ cpeum.htm, consultada el 10 de diciembre de 2014.

Ley Federal del Trabajo, http:/ / wmw.diputados.gob.mx/LeyesBiblio/index.htm, consultada el 14 de diciembre de 2014.

Decreto de reformas a la Ley Federal del Trabajo, Diario Oficial de la Federación, 4 de enero de 1980.

Exposición de motivos del Decreto que reforma, adiciona y deroga diversas disposiciones de la Ley Federal del Trabajo, Diario de Debates de la Cámara de Diputados, 4 de septiembre de 2012.

Exposición de motivos de la Ley Federal del Trabajo, Diario de Debates de la Cámara de Diputados, 12 de diciembre de 1968. V̧ 